\title{
o itinerário nas gạáxias de haroldo de campos
}

\section{The itinerary in Haroldo de Campos' Galáxias}

\section{Ana Ferreira ${ }^{1}$}

Resumo: O presente artigo promove uma análise comparativa da obra Galáxias de Haroldo de Campos (1984) e O itinerário de Benjamin de Tudela, um relato de viagem escrito entre $1160 \mathrm{e}$ 1173. Objetiva-se apresentar a hipótese de releitura do texto medieval em Galáxias, apontando semelhanças, diferenças e possíveis desdobramentos. Para tal, concentramos a investigação em três aspectos fundamentais: a estrutura de Galáxias; os elementos constitutivos na representação da realidade e seus equivalentes no passado evocado; o olhar do presente sobre o passado e os procedimentos poéticos na atualização do documento histórico.

Palavras-chave: Haroldo de Campos; Galáxias; Benjamin de Tudela; Poema neobarroco; Poema de resistência.

Abstract: This article suggests a comparative analysis of the book Galáxias by Haroldo de Campos (Brazil,1984) and The itinerary of Benjamin of Tudela, a travel book wrote between 1160 and 1173 . Our first objective is present the hypothesis that the poet realizes a rereading of this medieval travel writing, detaching resemblances, differences and some possible unfolding. For this, the investigation is concentrated in tree fundamentals aspects: the Galáxias structure; the constitutive elements on the reality representation and its equivalents in the evocated past; the present look over the past and the poetic procedures on the updated historic document.

Keywords: Haroldo de Campos; Galáxias; Benjamin of Tudela; Neobaroque poem; Resistance poem.

1 Ana Claudia Ferreira Martins de Souza é Bacharela em Letras (português e espanhol) pela Universidade de São Paulo. Autora dos livros Amadora (2001) e Carne Crua (2004), e das peças de teatro As Priscillas de Elvis (1996), Dueto do Ciúme (1998), entre outras. E-mail: ana.ferr@hotmail. com. 
e começo aqui e meço aqui este começo e recomeço e remeço e arremesso e aqui me meço quando se vive sob a espécie da viagem o que importa não é a viagem mas o começo da por isso meço por isso começo escrever mil páginas escrever milumapáginas para acabar com a escritura para começar com a escritura para acabarcomeçar com a escritura por isso (...)

(CAMPOS, 2011, frag. 1).

É recomeçando que Haroldo de Campos inicia Galáxias, um começo aberto que continua o que vem antes do conector " $\mathrm{e}$ ", antes do "aqui" indefinido em que se encontra o poeta que anuncia sua viagem e busca escrever um livro. A ideia de travessia aparece em "acabarcomeçar": na fusão de fim e começo, eis o barco para a "viagem maravilha". O viajante que parte e começa a viagem medindo lembra Cristóvão Colombo, que em seus Diários (14921493) relata a travessia do Atlântico rumo às utópicas Índias, interpretando sinais de proximidade de terra e contando milhas com traços de poesia, como se confere no registro do dia 15 de setembro de 1492: "Navegó aquel día con su noche veintisiete leguas su camino al Oueste y algunas más. Y en esta noche al principio de ella vieron caer del cielo un maravilloso ramo de fuego en la mar, lejos de ellos cuatro o cinco leguas" (COLÓN, 1991, p. 20).

O segundo verso - "e aqui me meço" - pode ser pensado como o poeta que calcula o lugar da linguagem no branco do papel, ou dosa a mescla de prosa e poesia, como o viajante que se prepara e calcula os kilômetros, milhas, léguas a percorrer, ou "parasangas", medida referida nas jornadas do judeu espanhol Benjamin de Tudela: de Narbona a Béziers "são quatro parasangas" (TUDELA, 2017, p. 43). O itinerário de Benjamin de Tudela é um relato de viagem escrito entre 1160 e 1173, e seu autor, um viajante judeu, não busca conquistar nem descobrir terras, é apenas um visitante ocasional e suas notas foram provavelmente escritas "ao sabor dos acontecimentos", ou seja, durante o trajeto. Além de possíveis interesses comerciais, o propósito Benjamin é visitar a Terra Santa e registrar o número e condições de vida dos judeus em cada cidade visitada. Ainda que os Diários de Colombo e $O$ itinerário de Benjamin de Tudela sejam documentos históricos, a aproximação de Galáxias com os relatos de viagem é possível a partir da partilha de características fundamentais de gênero, composição, estilo e tópicas. 
O segundo verso segue uma reflexão ambígua sobre a condição de se viver sob a "espécie da viagem", que tanto diz respeito ao tipo da viagem e ao espírito peregrino quanto ao gênero literário do livro a se compor. Ainda, "quando se vive sob a espécie da viagem" acumula o sentido de "dinheiro vivo"; e se pensarmos que Mallarmé "comparou a palavra à moeda que passa de mão em mão e se gasta, perdendo o valor e o brilho" (PERRONE-MOISÉS, 2000, p. 32), viver sob a "espécie da viagem" sugere desgaste, o que levaria o poeta a propor o restauro do sentido das palavras e da viagem mesma em uma "nova poesia" ou "nova prosa". A "nova poesia" foi vislumbrada por Benedetto Croce: "Uma vez refeito o homem, refrescado o espírito, uma vez surgida uma nova vida de afetos, surgirá então, se surgir, uma nova poesia" (CROCE, 1922, p. 241 apud BOSI, 1983, pp. 147-148), ideia citada no diário de cárcere de Antonio Gramsci, que frente à maré do caligrafismo na Itália, agrega: "a poesia não gera poesia", é preciso "refazer o homem" (GRAMSCI, 1974, pp. 219-220 apud BOSI, 1983, p. 147). A "nova prosa" foi anunciada pelo próprio Haroldo de Campos, em 1964, no quarto número da revista Invenção, quando começava a compor Galáxias. Sem renunciar aos princípios e técnicas fundamentais do concretismo poético, o projeto se orientaria frontalmente rumo à vida cotidiana, retomando recursos como a figuração, a colagem e o discurso narrativo, projeto que Jorge Manzi Cembrano denomina "nova prosa semi-abstrata", concebida como uma forma possível ou viável numa situação de crise (CEMBRANO, 2019, pp. 87-92).

Sopram os ventos da literatura árabe nas "milumapáginas" que pressupõem o Livro das mil e uma noites, e o começo da viagem de Galáxias é um recomeço qual o do poema circular de Mallarmé (1897) "que está sempre recomeçando como o mar no verso de Valery" (CAMPOS, 1969, p. 17), e como o recomeço do marinheiro Sindbad, "que parte novamente depois de cada viagem: ele quer que a vida lhe conte novas e novas narrativas" (TODOROV, 2018, p. 130). Cabe adiantar que o propósito do viajante que recomeça em Galáxias não é conquistar, mas visitar terras, e seu relato não se espelha nos grandes aventureiros nem nos relatos "imaginosos" como os de Jean de Lery ou Hans Staden, mais remetendo aos "diários escritos ao sabor dos acontecimentos ou de interesses comerciais determinados, por visitantes ocasionais" (SÜSSEKIND, 1990, p. 60), donde Campos segue o paradigma dos relatos de viagem com o qual dialogam os ficcionistas e historiadores do século XIX, objetos de Flora Süssekind em O Brasil não é longe daqui - O narrador, a viagem. 
Numa breve retrospectiva da ficção brasileira influenciada pelos relatos de viagem, notamos que na primeira metade do século $X X$, a dimensão oceânica do sertão e sua travessia substitui o Atlântico em algumas obras literárias, mas ecos das crônicas de Conquista são detectáveis, por exemplo, em Vidas secas (1938) de Graciliano Ramos². Na segunda metade, Haroldo de Campos resgata os acontecimentos e o viajante ocasional dos ficcionistas do século anterior, e a viagem é transatlântica e literária nas Galáxias, livro destacado por Flora Süssekind como uma das poucas publicações do período que apresenta um caráter crítico e reflexivo: "Viagem fortuita e forçosa num território bem pouco percorrido pela prosa naturalista e biográfica dos anos 70: a linguagem" (SÜSSEKIND, 1985, p. 63 apud GARCIA, 2005, p. 73).

A noção de diário de bordo e caderno de notas permeia todo o livro de Haroldo de Campos, inclusive incorporando trechos do diário de viagem de Bashô e da agenda de Che Guevara, nos fragmentos 29 e 32, respectivamente. No fragmento 8 , "isto não é um livro", o poeta nega o "livro de viagem" e faz referência a Baedeker, um famoso representante do gênero "guia de viagem":

isto não é um livro de viagem pois a viagem não é um livro de viagem pois um livro é viagem quando muito advirto é um baedeker de epifanias quando pouco solerto é uma epifania em baedeker pois zimbórios de ouro (...) (CAMPOS, 2011, frag. 8).

Karl Baedeker (1801-1859) era autor e editor alemão de uma famosa série de guias de viagens que estampavam seu nome no título, com encadernação vermelha, letras douradas, e classificação dos pontos turísticos e

2 Em Vidas secas (1938) de Graciliano Ramos, ecos das crônicas de Conquista podem ser percebidos na oscilação de Fabiano entre ser homem ou bicho, que remete à polêmica de Fray Bartolomé de Las Casas sobre a classificação dos indígenas americanos pelos europeus conquistadores: se são animais não se pode com eles guerrear; se são humanos, são donos da terra. A questão da palavra escrita como instrumento de poder e dominação remete ao uso da escrita dos europeus sobre as sociedades ágrafas, assim como a exploração persistente, e as referências de Fabiano às personagens das classes dominantes como "brancos". Também a circularidade da obra, marcada pela seca, ecoa o "tempo das frutas" dos indígenas; ainda o vocabulário restrito dos personagens, as superstições, a religião, e finalmente o vislumbre da cidade grande como paraíso terreal parecem influências dos cronistas conquistadores. Ecos semelhantes das crônicas de Conquista são detectáveis no tríptico poético Cão sem plumas (1950), O rio (1953) e Morte e vida severina (1956) de João Cabral de Melo Neto. 
hospedagens por "estrelas", apresentação que merece atenção, visto que o almejado "livro" é vermelho no fragmento 39, "circulado de violeta", donde no texto escrito no dia 2 de agosto de 1964, o poeta teria vislumbrado seu "livro" com a capa de Baedeker e o texto galáxias de estrelas inclassificáveis. No período em que Galáxias foi escrito, o empréstimo da capa vermelha de Baedeker pode ser interpretado como ironia à apreensão aleatória de livros de autores russos ou de capas vermelhas ocorridas durante a ditadura militar no Brasil3. Em Galáxias, o nome próprio Baedeker é tomado como sinônimo de guia, e na biografia de A educação dos cinco sentidos (1989), Haroldo de Campos se refere às suas viagens como "epifanias e antiepifanias"4. Logo, "baedeker de epifanias" seria um guia de viagem feito de epifanias.

A partir dessas considerações, elaboramos uma análise de Galáxias, de Haroldo de Campos, obra de vanguarda publicada integralmente em 1984, porém escrita entre 1963 e 1976. Sendo a matéria do livro muito vasta e passivel de infinitas interpretações e correlações, a análise faz um recorte possível de Galáxias e investiga uma suposta releitura de $O$ itinerário de Benjamin de Tudela (1160-1173), um documento histórico classificado como "guia de viagem", que supomos um dos guias de Haroldo de Campos no processo de composição. Além da partilha de características fundamentais de gênero, composição, estilo e tópicas, coincidem algumas cidades e talvez equivalências e desdobramentos da rota de Tudela no roteiro de Haroldo de Campos, dedutíveis na comparação da cronologia da redação dos fragmentos de Galáxias com o percurso de Benjamin. Objetiva-se apresentara hipótese de releitura do texto medieval, apontando semelhanças, contrastes e possíveis preenchimentos, espelhamentos, dobras. Para tal, concentramos a análise comparativa em três aspectos fundamentais: a estrutura de Galáxias, o percurso espacial-literário do narrador, e a devoração e

3 As razões para a apreensão de livros variavam: "por falarem de comunismo (mesmo que fosse contra), porque o autor era persona non grata pelo regime, por serem traduções do russo, ou simplesmente porque tinham capas vermelhas. Flavio Suplicy Lacerda, o primeiro ministro da educação e cultura da ditadura militar (1964-1966), assumiu o ministério com um histórico de censura e repressão a livros, inclusive usando fogo para a purificação de ideias". Entre abril de 1964 e março de 1979, mais de seis mil livros foram confiscados. Um dos casos mais conhecidos é o do editor e dono da Editora Civilização Brasileira, Ênio Silveira, preso sete vezes durante a ditadura (CASTRO, 2017, pp. 25-77).

4 Haroldo de Campos refere-se às suas viagens como "Epifanias e antiepifanias" desde a de 1959, quando foi à Europa com sua companheira Carmen e seguiram o roteiro de Ezra Pound: "Fizemos o roteiro dos Cantos de Pound" (CAMPOS, 2010, p. 283). 
transformação da tradição, ou seja, investigamos os elementos constitutivos na representação da realidade e seus equivalentes no passado evocado, o olhar do presente sobre o passado, e os procedimentos do autor na atualização do documento histórico.

\section{o relato de viagem em ơaláxias}

No artigo "Revendo estrelas em outras galáxias", Cristina Monteiro de Castro Pereira situa entre Homero e Joyce a influência de Dante na composição de Galáxias, e chama a atenção para o cenário do poema de Campos, que não é o céu nem o inferno, é o mundo terreno: "trata-se de uma viagem epifânica como a de Dante, mas o percurso é terreno, sem deuses. O sistema de valor é outro" (PEREIRA, 2010, p. 63). O percurso terreno de Galáxias compreende muitas cidades, aspecto que o aproxima da relação atribuída a Marco Polo, que, no entanto, não teria escrito sua experiência durante a viagem, mas a ditado depois a Rustichello de Pisa, diferentemente do poeta de Galáxias, que se propõe a escrever seu relato durante o deslocamento poético, ou, em termos de percurso terreno, a tudo registrar no decorrer da viagem, mais se aproximando de O itinerário de Benjamin de Tudela (1160-1173) - um documento histórico com traços literários que talvez se encontre sob as muitas camadas textuais de Galáxias, segundo a ideia de palimpsesto.

Anterior a Marco Polo em quase um século, a relação de viagem do judeu Benjamin de Tudela foi escrita durante a conquista da Península Ibérica, de onde sai o viajante. Seu propósito não é descobrir nem explorar novas terras, mas ir à Terra Santa e conhecer as condições em que vivem os judeus espalhados pelo mundo. A viagem se estende por aproximadamente treze anos, e o texto resulta num "guia de viagens", com informações como distância de uma cidade a outra, posição geográfica, origem e costumes dos habitantes, descrição e história das cidades, eventos e fatos significativos, e, sobretudo, o número de judeus de cada lugar e os nomes próprios dos "cabeças" das congregações judaicas, dados precisos que implicam em notas realizadas ao longo da viagem. O itinerário compreende cerca de duzentas cidades, e inclui algumas não visitadas por Benjamin, cujas informações não se baseiam no que viu, mas no que ouviu, e resultam vagas, inexatas ou fantasiosas. 
Tendo em conta a distância entre um texto medieval e Galáxias do ponto de vista do gênero, partimos das perguntas: Como este autor moderno se vale de um documento histórico na composição de uma obra literária? Considerada a intertextualidade, de que maneira Haroldo de Campos aproveita a imaginação histórica para pensar o presente?

Equivalente a um "caderno de viagem", a escritura de Campos parece atualizar a viagem de Benjamin de Tudela, ou melhor, parece presentificá-la através da paródia. No texto "Paródias do céu: a poesia, a crítica e a tradução de Haroldo de Campos", Eduardo Jorge assinala que a paródia surgiria na obra de Campos, não apenas como um recurso estilístico, mas encenando um canto paralelo, tendo em conta o étimo grego 'Para Ode', segundo sugestão do próprio autor: "Paródia que não deve ser necessariamente entendida no sentido de imitação burlesca, mas inclusive na sua acepção etimológica de canto paralelo" (CAMPOS, 1980, p. 129 apud JORGE, 2019, p. 88). "Haroldo de Campos enfatiza que se valeu do conceito no final dos anos 1960", quando "começava a circular no Ocidente a perspectiva de Mikhail Bakthin definida em termos de dialogismo e polifonia" (CAMPOS, 1980, p. 129 apud JORGE, 2019, p. 88).

Embora o relato de Benjamin de Tudela seja um documento histórico, apresenta muitos traços de ficção, valendo-se de empréstimos e incorporação de relatos orais, supostamente percebidos por Campos como rudimentos de dialogismo e polifonia, abundantes em Galáxias, entre outros aspectos partilhados com Tudela. Dessa maneira, na defesa de uma história sincrônica e talvez compondo um "canto paralelo" com uma obra fundante do gênero "guia de viagem", o viajante de Galáxias também segue por mares, rios e terras da linguagem, porém não informando o número de judeus vivos em cada cidade como faz Tudela, mas um sem número de judeus, ciganos, comunistas, artistas, homossexuais mortos pelo nazismo e fascismo na Europa. Em particular, supomos que Haroldo de Campos espelha as notas de Tudela quanto ao número e condição dos judeus no século XII, enfocando - Holocausto do século XX. A partir destas considerações, podemos reconhecer em Galáxias oprimidos equivalentes aos das supostas matrizes, e convidamos o leitor a pensar os problemas do presente a partir da reflexão de Haroldo de Campos sobre o passado representado por seus predecessores em questões como processos de colonização, subjugação de povos e etnias, diásporas, ditaduras, testemunho e memória. Afinal, de acordo com Lukács, 
"É indispensável, em toda grande arte, representar os personagens no conjunto de relações que os liga, por toda parte, à realidade social e a seus grandes problemas." (LUKÁCS, 2012, p. 188). Galáxias foi escrito durante a ditadura militar no Brasil (1964-1985), e uma possível acepção da obra é a poesia de resistência, já que dotada de sentido crítico, de valorização da memória coletiva, e de reflexão sobre a linguagem.

Uma observação a respeito do tempo no processo criativo de Haroldo de Campos também nos serve de argumento no cotejo com $O$ itinerário de Benjamin de Tudela: o formante inicial de Galáxias foi escrito em 18 de novembro de 1963: "Ali o projeto do livro já está posto, embora, como sabemos, seu autor ainda vá levar anos para escrevê-lo" (SOUZA, 2017, p. 191). É curioso verificar que Haroldo de Campos levará treze anos para concluir Galáxias (1963-1976), processo que praticamente coincide com a duração da viagem de Benjamin de Tudela (1160-1173), cujo relato foi traduzido para o português por Jacó Guinsburg, amigo com quem Campos "conversou muito sobre Israel". Em entrevista concedida a Gênese Andrade, Guinsburg comenta: "tive um diálogo muito grande com o Haroldo no campo da literatura hebraica, da literatura judaica" (ANDRADE, 2010, p. 136).

\section{caleidoscópio neobarroco}

Concebido como "caleidoscópio", Galáxias integra cinquenta fragmentos, ou cantos, sem títulos nem numeração de páginas; o primeiro e o último fragmento são chamados formantes, e escritos inteiramente em itálico, o que os diferencia dos demais.

No livro A arte no horizonte do provável, de 1969, Haroldo de Campos aborda a provisoriedade do estético, trazendo ao debate o projeto do "multilivro" de Mallarmé: "As folhas desse livro seriam cambiáveis, poderiam mudar de lugar e ser lidos de acordo com uma combinação determinada pelo autor-operador". Tal projeto aboliria a ideia de obra conclusa e instalaria o transitório, dando ao leitor possibilidades de escolha, qual ao intérprete na Troisième Sonate para piano, do francês Pierre Boulez (1957), as possibilidades são "delimitadas pelo compositor e integradas em 'formantes'". A introdução do acaso é também basilar na Klavierstuck XI de Karlvinz Stockhasen (1956), cuja partitura tem aspecto de "mapa ou planta, que se desenrola e se adapta a uma estante portátil" (CAMPOS, 1969, pp. 18-21). Em Galáxias, Haroldo 
de Campos experimenta e integra tais ideias, integrando a permutação e o movimento do "multilivro" de Mallarmé, o acaso balizado através de "formantes" por Boulez, a viagem mesma pressupõe o aspecto de "mapa" da partitura de Stockhasen, e o jogo proposto por John Cage está textualmente presente. A ausência de pontuação e de maiúsculas garante fluência e unidade, e neobarrocamente a poesia de Campos concreta-se na viagem literária de Galáxias, talvez esboçando graficamente margens de mares e rios. Assim, cada canto de Galáxias seria uma praia, sugerida visualmente no conjunto dos "versículos" não justificados na margem direita, de forma que 0 texto em versos espraiados resulta num mar de palavras. Particularmente, na comparação com $O$ itinerário de Benjamin de Tudela, as praias graficamente sugeridas se coadunam imageticamente com as margens de mares e rios em que se assenta grande parte das cidades visitadas por Benjamin. E considerando o livro na totalidade, a variação do número de versos (entre 40 e 46) que se nota nas margens inferiores ao virar das páginas, em visão panorâmica cinematográfica, se assemelharia à variação topográfica, ou o contorno da paisagem branca, o horizonte que o viajante-leitor vê, e o canto acima é um céu de palavras, uma "paródia do céu".

Como é sabido, Haroldo de Campos, idealizador do movimento da poesia concreta ao lado de Augusto de Campos e Décio Pignatari, distingue Galáxias como poema neobarroco. Se por um lado, a poesia concreta "postulava a exploração de elementos gráfico-visuais por meio de uma noção de poema como ideograma", por outro, as "experimentações neobarrocas" de Campos "foram um modo de ampliar o debate sobre a questão da visualidade e de, ao mesmo tempo, propor uma reformulação dos paradigmas da poesia concreta" (OLIVEIRA, 2011, p. 49). O declarado neobarroco é perceptível em Galáxias no arranjo das palavras, nos contrastes, nos símbolos e metáforas, no erotismo, nas idas e vindas, no aproximar e distanciar do olhar do poeta. Segundo Dhynarte Albuquerque Filho no artigo "Haroldo e as Galáxias: um caso concreto de barroco", os temas abordados em Galáxias são caros a Gregório de Matos: "religião, temporalidade, agoridade, cotidiano, dualidade, alegoria" (2006, p. 190).

Entre os muitos paralelismos em Galáxias, destacamos uma possível duplicidade na configuração do guia simbólico, que evoca a Comédia - obra poética em que Dante Alighieri tem por guia Virgílio-, e quiçá, paralelamente, 
O itinerário de Benjamin de Tudela - um documento histórico classificado como "guia de viagem", talvez um guia icônico de Campos. As duplicidades, multiplicidades, contrastes, e transfigurações se estendem a outros aspectos de Galáxias, como se nota na completude fragmentada, na poesia em prosa, na temporalidade, na representação da figura feminina, no livro de viagem que é a própria viagem. O texto galáctico inclui relatos orais, manchetes de jornais, obras de arte, monumentos, edificações, percepções, sensações, e mescla vários idiomas ao português, além de criar palavrasvalise e neologismos. No fragmento 29, o "poeta sem lira" assume-se póslírico e, na tessitura de Galáxias encontramos um mosaico de citações e alusões a autores caros a Haroldo de Campos, traço comum a The waste land, deT. S. Eliot, e a The Cantos de Ezra Pound, que no desmonte do projeto lírico romântico, substituíram a "experiência em primeira mão da personalidade lírica pelas leituras" (BRITTO, 2000, p. 127), em termos de Paulo Henriques Britto, que no ensaio "Poesia e memória", as enfatiza como obras de grande influência na poesia brasileira, a partir dos anos 50, "graças ao exemplo e à militância dos concretistas". E a intertextualidade em Galáxias também pode ser pensada como poesia coletiva. "Diante da pseudototalidade forjada pela ideologia, a poesia deverá 'ser feita por todos, não por um', era a palavra de ordem de Lautréamont", fazer coletivo que, como observa Alfredo Bosi, não se realizou na forma de criação grupal, mas "acabou fazendo-se, de algum modo, como produção de sentido contra-ideológico", o que seria "uma forma de resistência simbólica aos discursos dominantes" (BOSI, 1983, p. 144).

Em "Construyendo puentes: Haroldo de Campos como mediador cultural entre Brasil e Hispanoamérica", Jasmin Wrobel observa que em Galáxias as referências a obras de autores canônicos como Homero, Dante, Shakespeare ou Goethe se entretecem com referências à poesia russa, japonesa e com a cultura folclórica brasileira, chamando a atenção para a descentralização estrutural como reflexo da ideia de uma literatura desierarquizada, sem centro nem periferia (WROBEL, 2015, p. 32). Quanto ao paideuma ${ }^{5}$ de Campos, inclui "nomes esquecidos e negligenciados de nossa literatura", a começar por Gregório de Matos. Sendo O itinerário de Benjamin de Tudela um documento histórico, naturalmente seu autor não constaria no paideuma,

5 Sobre o termo Paideuma: "tomou o sentido do elemento ativo de uma era, o complexo de ideias que é, num dado momento, germinal, que alcança a época seguinte, mas condicionando ativamente todo o pensamento e ação do seu tempo" (PERRONE-MOISÉS, 1998, p. 65). 
porém, Benjamin de Tudela é um nome esquecido e negligenciado, apesar da influência nas relações dos cronistas da Conquista, fato que supomos atraente a Campos. Ademais, é sabido que Haroldo de Campos tanto experimenta como muito reflete sobre a questão dos gêneros, de modo que, em Galáxias, de acordo com Wrobel, o diálogo com uma obra canônica se realiza no mesmo nível com um mito ou lenda. Assim, às escolhas de Campos levantadas por Leyla Perrone-Moisés em Altas literaturas (1998), e às espécies literárias assinaladas pela crítica como fontes de Galáxias, agregaríamos as crônicas de viagem, em especial, $O$ itinerário de Benjamin de Tudela (1173), documento que supomos um dos guias na composição deste livro permutável, longo poema em prosa, ou "proesia", em definição de Caetano Veloso, que no exílio em Londres, recebeu a visita de Haroldo de Campos, em $1970^{6}$.

\section{o itinerário permutável: um canto paralelo?}

As reflexões de Haroldo de Campos no citado ensaio "A arte no horizonte do provável", as percebemos experimentadas em Galáxias, e supomos que percebidas pelo poeta no relato de Benjamin de Tudela, pelo menos rudimentos dos conceitos tratados. O aspecto de "mapa ou planta" da partitura de Stockhasen pressupõe-se na viagem e na unidade de Galáxias, e a possível leitura aleatória do livro equivale ao passeio do olhar do viajante sobre um mapa a escolher o destino. No entanto, tal como o caminho do viajante, a escrita do poeta é linear, a partir do que, lançamos a hipótese de que o itinerário de Benjamin de Tudela foi um possível guia no processo da composição de Galáxias, e organizamos a análise do roteiro da viagem segundo a cronologia de redação dos fragmentos, mas como se tivéssemos nas mãos os mapas dos dois textos que confrontamos.

6 No texto "Viajando com Haroldo" de Leyla Perrone-Moisés, os leitores de Galáxias podem reconhecer algumas passagens, como a visita ao museu Villa Giulia de arte etrusca, em Roma e conhecer o surgimento do fragmento 43, "uma das mais belas páginas das futuras Galáxias", a que Leyla Perrone-Moisés teve o prazer de ver Haroldo de Campos escrever em janeiro de 1970, num voo de Roma a Londres. Conta Leyla que Haroldo, lendo um jornal italiano, de repente encontrou algo que o entusiasmou: a notícia policial sobre "uma mulher alta, loura platinada, de minissaia e saltos agulha", que ao fugir dos carabinieri, tropeça, quebra o salto e perde a peruca, revelandose uma travesti. "Haroldo sacou imediatamente um bloquinho e pôs-se a escrever". Em Londres encontrariam Caetano Veloso. (PERRONE-MOISÉS, 2010, pp. 49-58). 
Escrito o primeiro formante de Galáxias em 18 de novembro de 1963, no dia seguinte, a redação de Haroldo de Campos situa o viajante em Granada ao compor o segundo fragmento, ou canto. E no mesmo dia se lança aos mares e escreve o terceiro fragmento, "multitudinous seas". Seguindo a cronologia da redação dos fragmentos, a primeira cidade que Campos representa em Galáxias é Granada, no sul da Espanha, a cidade de onde partiu Cristovão Colombo em 1492, a serviço del Rey, e a cidade onde Federico García Lorca foi assassinado pelas forças de Franco em 1936. O fragmento "reza calla y trabaja", a católica Granada recebe a visita do embaixador inglês em 1959, mas reverbera o franquismo, versão repaginada do Santo Ofício atuante no período de conquista das Américas vinculando "religión y pátria". O texto associa a cal da cidade, o branco do muro e o da página, à morte do poeta, ao silêncio e à perda de memória. Em Granada nada se informa, só se "reza calla y trabaja", resgatando valores e práticas medievais como religião, censura, perseguição e morte às vozes dissidentes, e ainda a expulsão dos mouros e judeus das terras espanholas, onde nasceu e viveu o judeu Benjamin, que leva no nome sua cidade Tudela. O canto de Campos em Granada incorpora versos do poema "El crimen fue en Granada" do espanhol Antonio Machado, escrito quando Federico García Lorca foi assassinado - "ipobre granada!". Dessa maneira, pode-se supor que no contraste aos judeus vivos contados por Tudela, o sujeito plural de Galáxias tanto empresta versos de Antonio Machado como parece dar voz a León Felipe, ideia que se ancora no texto homenagem de Rafael Alberti a este poeta peregrino anacrônico e obscurecido pelo fascismo - expatriado político, León Felipe teve sua obra proibida na Espanha, o que o converteu em porta-voz dos exilados. Rafael Alberti, também um dos "españoles del éxodo", discorre sobre três encontros com León Felipe. O primeiro reuniu Lorca, Pablo Neruda e Miguel Hernández, entre outros poetas; e no segundo encontro, a estupefação: "Pisó León otra vez la tierra de España. ¡Y Federico ya no estaba!". Relata Alberti que León Felipe passou aquele outono contando mortos: "Contando muertos por las plazas y parques, contando niños muertos en los hospitales, contando muertos en los carros de las ambulancias, en los hoteles, en los tranvías, en el Metro" (ALBERTI, 1976). O clamor por justiça e os muitos judeus, os desvalidos, os oprimidos que povoam a poesia de León Felipe, assim como sua trajetória peregrina, também nos são argumentos, visto que o sujeito pós-lírico de Galáxias igualmente se espanta com a injustiça, e conta judeus mortos pelo nazismo, 
ao contrário do peregrino Benjamin de Tudela, que conta judeus vivos espalhados pelo mundo no século XII. Por exemplo, em Marselha constam "duas congregações com cerca de trezentos judeus"; em Gênova, "vivem dois judeus" (TUDELA, 2017, p. 46); em Pisa "há cerca de vinte judeus"; Roma "contém cerca de duzentos judeus" (p. 47); em "Bagdá há cerca de quarenta mil judeus e eles vivem em segurança, prosperidade e honra sob o grande califa" (p. 97). Em Rudar, "há cerca de vinte mil israelitas, e entre eles doutos e homens ricos. Mas os judeus lá vivem sob grande opressão" (p. 112). A opressão aos judeus é também registrada em Salônica (p. 6o); em Sinon Potamo os "valaquianos roubam judeus mas não os matam" (p. 59); e em Constantinopla, curtidores "despejam sua água suja diante das portas das casas judaicas e sujam os bairros dos judeus [...] os espancam nas ruas e os tratam em todos os sentidos com rigor" (p. 64).

Observa Lucius Provase que a "escrita em galáxias é uma escrita não linear porque sua visão da História é não linear, não dicotômica. Inserese, na verdade, em uma multiplicidade de temporalidades e durações" (PROVASE, 2016, p. 79). O tempo galácteo de Haroldo de Campos é o "hojeamanhãontem", que mistura presente, futuro e passado; muitas coisas se passam paralelamente e o tempo se desdobra na interlocução de distintos momentos históricos, como ocorre em Granada, com ecos da conquista da Península Ibérica, da conquista da América, e da Espanha franquista, tudo isso no texto que focaliza um evento de 1959, e foi escrito no final de 1963, ano véspera do golpe militar no Brasil. Em janeiro de 1964, Haroldo de Campos começa a escrever "no jornalário", só concluído em 24 de julho; ou seja, a travessia no "mar morto de esgoto" é atravessada pelo golpe militar no Brasil, e quando Campos conclui a arrastada redação do quarto fragmento de Galáxias, o quinto, "mire usted", é prontamente escrito no mesmo dia. O poeta alcança a terra, e a primeira visão é a Mesquita de Córdoba que ecoa Bagdá e outras cidades árabes mencionadas por Tudela. Assim, considerando a sequência da composição dos fragmentos de Galáxias, após a travessia por mares vivos em cores "multitudinous seas" e pelo "mar morto de esgoto" do jornalário sem cores, "mire usted" no início do fragmento 5 tem efeito de 'terra à vista'. Em correlação com Granada, Córdoba é a cidade natal do poeta barroco Luís de Góngora, ao que vale lembrar que a "geração de 27" de Lorca foi um movimento literário restaurador da poesia gongoriana. $O$ texto começa realçando a herança islâmica na Mesquita e o "guia" de 
Galáxias informa: "yo soy el único arabista de córdoba". Além da detida descrição dos arcos da Mesquita, o poeta destaca o conjunto de portas que "remonta às dinastias de Abderramán e Almanzor, reis mouros que viveram na região" (PRAZERES, 2016, p. 194). Em contraponto, nos últimos versos, na "judería", o guia arabista descifrará para "um enchapelado cacho de velhas made in usa as letras hebraicas descacadas desoladas paredes pilhadas", ou seja, Campos destaca vestígios da presença de árabes e judeus expulsos de terras espanholas, tanto em 1492 como em 1940.

A figura do 'guia' atravessa Galáxias desdobrando-se em diversas formas: no fragmento 4, em Córdoba, é guia turístico; no fragmento 8, que correlaciona Genebra e João Pessoa, passa a "guia de viagens" ou "baedeker de epifanias"; e se converte em taxista em três ocasiões: no fragmento 19, "como quem escreve", comenta-se numa cama sobre o o que dissera um taxista lituano radicado no Brasil. No fragmento 21, "e brancusi", pousa o avião em Paris e logo aparece o taxista e a indicação do hotel em que morou Oscar Wilde. No fragmento 30, "pulverulenda", em Buenos Aires, vemos o taxista "parando entre lavalle e maipú", e, embora conte com uma passagem cômica, a atmosfera é de tempos sombrios: no jornal "la nación com manchetes bovinas", "mataram um transeunte bem na calle florida entrevero com pintores saídos do di tela", referente ao Instituto Torcuato Di Tella. Os verbos "mataram" e "saídos", e no verso seguinte o lema "religión y ordem", somados à presença do "presidente de estados unidos" passeando pelos jardins, sugerem a última ditadura militar na Argentina (1976-1983). A propósito, num comentário proferido durante o voo de Stuttgart a Paris, no fragmento 21, "e brancusi", Luiz Costa Lima enfatiza outro motivo de ordem política, referente ao golpe militar no Brasil: "Pela aliteração das batinas becas batas mandíbulas de saúva rilhando, a página nomeia o desfile das marchadeiras de espectral memória": os representantes do velho em nossa sociedade que, sob o eufemístico título de 'marcha da família com Deus pela liberdade', "manifestavam a disposição golpista que dispararia na noite de 31 de março de 1964" (LIMA, 1989, p. 348).

No século $X X$, é tempo de barbárie na "civilização" e a transmissão da memória se realiza por oralidade e também se inscreve em paredes e muros: No fragmento 10, "ach lass quatschen", o viajante encontra-se num bar onde três velhos senhores bebem e choram; os versos finais dizem que "brutos blondos bárbaros massacraram todos os juden de praga" e seus nomes 
cobrem uma parede: "nomessobrenomessobrenomesnobrenomes". Opostamente semelhante é a referência ao muro ocidental em Jerusalém no relato de Tudela: "os judeus que ali vêm escrevem seus nomes no muro" (TUDELA, 2017, p. 75). As referências a catacumbas e cemitérios israelitas em Galáxias também remetem às antigas tumbas de personalidades bíblicas visitadas por Benjamin de Tudela, a exemplo do fragmento 22, "hier liegt", ambientado em Toledo, onde se encontra a "catacumba romana de monteverde" e a inscrição na lápide "aqui jaz descansa em paz uma jovem judia". O poeta faz menção à "cartilha nazi que divide o mundo em ferozes anjos louros e dóceis demônios/ morenos memento lamento", e logo sabemos que Toledo é "zona de ocupación", onde "investigam a família inteira" e abundam "curas o guadias civiles". Cabe apontar no relato de Tudela, uma caverna em Hebron com seis sepulcros, todos com inscrições gravadas na pedra; primeiro os de Abraão, Isaac e Jacob, e logo: "'Esta é a tumba de Sara', 'Esta é a tumba de Rebeca', e 'Esta é a tumba de Lea'. Uma lâmpada arde dia e noite sobre as sepulturas na caverna. Encontram-se lá muitas urnas cheias de ossos de israelitas" (TUDELA, 2017, p. 81).

Há coincidências, aproximações e equivalências entre as cidades que compõem a viagem de Galáxias e as visitadas por Benjamin, a começar por Roma, onde mais tempo permaneceu, e onde o viajante de Campos também mais se demora, ocupando talvez sete dos cinquenta fragmentos.

Na estadia em Roma, Benjamin de Tudela destaca a "grande igreja que eles chamam de São Pedro de Roma", logo o palácio dos césares, o palácio de Vespasiano, refere os "oitenta palácios pertencente a oitenta reis que viveram lá", então descreve o Coliseu, e no subterrâneo "as catacumbas do rei Tarmal Galsin e sua consorte que lá se encontram, sentados em seus tronos, e com eles cerca de cem personagens reais. Todos embalsamados e preservados até o presente dia". Na igreja de São João de Latrão, Tudela destaca as "duas colunas de bronze tiradas doTemplo, trabalho manual do rei Salomão, estando cada coluna gravada com 'Salomão, o filho do rei David'". E em frente à igreja, "há estátuas de Sansão em mármore, com uma lança na mão, e de Absalão, o filho do rei David, e outra de Constantino, o Grande [...] de bronze, sendo o cavalo folhado de ouro" (TUDELA, 2017, pp. 51-52).

7 A parede tem referente na sinagoga Pinkas, no Museu Judaico de Praga, onde estão gravados os nomes de aproximadamente 80.000 judeus tchecos mortos no massacre nazista da Segunda Guerra Mundial. 
Curiosamente, os lugares referidos por Tudela ainda existentes no século XX não aparecem na Roma de Galáxias. Nessas ausências, o viajante de Campos parece completar as notas de Tudela, visitando outros locais e preenchendo espaços por ele deixados ou sumariados em demasia. Assinalamos as "muitas estruturas maravilhosas na cidade, diferentes de quaisquer outros no mundo. Incluindo tanto as suas partes habitadas quanto as ruínas" (TUDELA, 2017, p. 49). Comecemos pelas ruínas. No fragmento 11, "amorini", entre as ruínas da Pompeia soterrada pelas lavas do Vesúvio em 79 a. C. e depois escavada, o poeta vê a imagem de Priapo na Casa dos Vetti, diante da qual protestantes passam com pudor, pois o deus da virilidade tem um grande pênis ereto. A figura do "guia" ressurge na entrada do "vico del lupanare", e nas paredes tatuadas das "celae metriciae" eis a pequena prostituta fossilizada "sorrindo dentro do copo titillatio fellatio irruminatio". E se cem embalsamados acompanham rei e rainha nas catacumbas vistas por Tudela, na Roma de Campos vemos um casal abraçado no "sarcófagotálamo" do Museu de Villa Giulia - o Sarcófago dos esposos, arte etrusca do final do século VI a.C. (PRAZERES, 2016, p. 243). Talvez completando, ampliando e atualizando as informações do suposto guia icônico, os monumentos e estátuas referidos por Tudela não são os mesmos que constroem a Roma de Campos, mas esculturas, paredes, praças, igrejas, fontes e pontes de Galáxias igualmente contam história:

\begin{abstract}
(...) os repense saído à manhã friorenta fricção do frio nos poros e roma caindo da colina capitolina onde a vênus dedimármora capitolina tapa o sexo de mármore ogni riproduzione vietata e os muros de tijolos expostos e as ruínas de fraturas expostas colunas truncadas peristilos rotos sócos como ossos no fórum romano largado pelos deuses e na via (...) (CAMPOS, 2011, frag. 9).
\end{abstract}

No "vico degli scheletri" vai "o livro se fazendo nos muros qui tot scriptorum taedia", verso que incorpora parte de uma das inscrições da cidade de Pompeia, segundo nota de Gabriela Bandeira de Souza que traz a tradução integral: "Admira-me, parede, não teres caído em ruínas, tu que te aguentas o tédio de tantos escritores" (2017, p. 194). Deste modo, o livro vai se fazendo em Galáxias, tal qual na Roma de Tudela é perpetuada a batalha das Termas do Coliseu que o rei mandou esculpir nas paredes do palácio "para mostrar ao mundo a guerra dos dias antigos" (TUDELA, 2017, p. 50). O registro da 
passagem de Tudela por Roma termina com uma nota que também deixa lacunas: "Existem lá muitos outros edifícios e um cem número de coisas para ver" (TUDELA, 2017, p. 52). E como num "canto paralelo", compondo um duo com Tudela, o viajante de Campos nos mostra em Roma "muitos outros edifícios" e vemos mais um "cem número de coisas": palazzi barrocos casarõescortiços, villa giulia, via del consolato, via di ripetta, casa dei vettii, casa de la venere, casa della moda sportiva, vico del lupanare, vico degli scheletri, templo de apolo, calçada delle belle arti, ossos no forum romano, piazza di trevi, em cada canto uma piazza em cada piazza uma fonte, bazar beneficente, ristorante trevi, ristorante alergo, gioie bar, banca tito avgvsto, etc, etc.

Imaginando os mapas das rotas de Tudela e Campos, as colunas de ouro do Templo de Salomão transferidas para igreja de São João de Latrão em Roma, descritas no relato de Benjamin, e a sinagoga de Jerusalém reconstruída em Schafjathib, a que chamam "La Trasplantada", feita "com terra de Jerusalém e suas pedras" (TUDELA, 2017, p. 107), chamam a atenção para as transplantações de Galáxias: "na paris que os americanos trouxeram para greenwich village e puseram ketchup por cima"; e "veio da catalunha uma igreja inteira para reconstruída dentro do museu café budapest restaurant", nos fragmentos 24 e 26, respectivamente. Também os empréstimos de Tudela seriam sedutores à intertextalidade de Campos, a exemplo da menção do primeiro ao "palácio fora de Roma (que diz ser de Tito)". Em nota de rodapé, Jacó Guinsburg esclarece tratar-se de "uma adaptação medieval muito popular da obra de Flávio Josefo", e comenta que "Benjamin incorpora por vezes, em seu itinerário, lendas fantásticas que lhe contaram ou foram registradas por seus predecessores" (TUDELA, 2017, p. 50). Além disso, constam transcrições de passagens bíblicas e relatos que lhe foram oralmente transmitidos, como se verifica na passagem por Naisabur, a citação de "2 Reis 18, 2". Pouco adiante, Tudela relata a história de R. Moisés, um judeu arqueiro feito escravo de um cavaleiro do rei da Pérsia, libertado depois de uma exibição de sua habilidade. "Esse mesmo R. Moisés contou-me todas essas coisas", revela Benjamin no final do relato, como em várias outras passagens (TUDELA, 2017, pp. 119-124). Daí, supomos que empréstimos, transcrições e relatos alheios na obra de Tudela tenham soado instigantes a Haroldo de Campos enquanto noções de dialogia e polifonia, conceitos amplamente trabalhados em Galáxias. 
Muito se passa no tempo acelerado não contado nos tantos relógios espalhados por Galáxias, os quais podem ser vistos como evolução e multiplicação das edificações projetadas para a contagem do tempo, muito observadas por Tudela. Assinalamos em Roma "o Coliseu", composto por "365 seções, de acordo com os dias do ano solar" (TUDELA 2017, p. 50). Em Damasco, na construção que era um palácio de Bem Hadad, "há uma parede de cristal de mágico lavor, com aberturas de acordo com os dias do ano, e quando os raios do sol entram em cada uma delas, na sucessão diária, as horas do dia podem ser ditas por um dial graduado" (TUDELA, 2017, p. 86); e em Balis tem a Torre de Balaam, "que ele construiu para dizer as horas dos dias" (TUDELA, 2017, p. 90). Em Galáxias, tais edificações estariam reduzidas e multiplicadas nos muitos relógios de pulso, como vemos no fragmento 9, "açafrão", em Roma, um "capitão de aviação comercial tentando revender relógios pirateados".

Entre os supostos desdobramentos de localidades ou eventos mencionados por Tudela, destacamos em Galáxias o espelhamento de performances transraciais: no fragmento 22, "hier liegt", em Toledo, realçamos a menção a uma transfiguração performática: "falsa japonesa fazia strip-tease numa boîte de bâle tirava a peruca e ficava sendo uma alemãzinha de frankfurt"; no fragmento 27, "sob o chapéu", em San Francisco, "a mulata de tretas tetas mais a ruiva de pipilos mamilos encornam o templário tomate"; no canto 28, "ou uma borboleta", é situado num cabaré em Soho, "cleópatra the stripper degusta uma banana fellatio-style e romanina ergue os seios nas mãos e os mordisca". No fragmento 34, "calças cor de abóbora", em Washington, a um dólar se vê "duas moças mecânicas", uma "cara láctea de bebê loiro", outra "negríssima nigérrima". Tais passagens performáticas transraciais em Galáxias parecem distribuir um evento anual de Constantinopla registrado por Tudela: no Hipódromo, "homens de todas as raças do mundo se apresentam ao rei e à rainha, com prestidigitação ou sem prestidigitação" (TUDELA, 2017, p. 62).

A disposição de outras localizações coincidentes colabora com a hipótese de que o itinerário de Tudela seria uma rota no processo da redação de Galáxias, pois além de demorar-se em Roma, os países não visitados por Benjamin (como França, Rússia e Alemanha) foram escritos por Campos em sequência, são descritos vagamente, e repletos de vozes. Como Tudela, que menos descreve e mais discorre sobre as cidades não visitadas segundo o 
que ouviu, certas passagens de Galáxias são preenchidas por conversas, e o tempo verbal passa do presente ao pretérito. Por exemplo, no fragmento 19, "como quem escreve", conta-se o que dissera um taxista lituano sobre o inverno que derrotou os alemães na Rússia, onde Tudela não pisou, mas soube que é um país tão frio que "encontram-se lá pessoas que perderam a ponta do nariz devido à geada" (TUDELA, 2017, p. 148), registro que o taxista de Campos parece dilatar: "orelhas apodreciam e caem a ponta do nariz também as pernas". Já no fragmento 23, "neckarstrasse", a conversa é divertida: "o jantar na casa de goethe você precisava ver como shiller ria e eu". O cenário e os ilustres personagens certamente representam um jantar na casa de Goethe, com Johann Heirich Voss e com Schiller. O assunto que embala as risadas é "o Sófocles de Holderlin", que "eram na verdade o 'epitáfio irônico' de uma determinada visão de poesia e do decorum artístico", esclarece e conclui Haroldo de Campos no ensaio "A palavra vermelha de Holderlin", que termina com sua própria "tradução (recriação)" da "Antígone de Hoelderlin: Ato I - Cena I" (CAMPOS, 1969, pp. 93-107). Curiosamente, no já citado $O$ Brasil não é longe daqui, Flora Süssekind menciona outro interessante frequentador da casa de Goethe, citando Lezama Lima: "cada viagem de Humboldt parece resumir-se numa visita a Goethe". Em "Recuerdo de Humboldt", texto de 1957, Lima sugere que "as descobertas, investigações e tropeços" de Humboldt se esclareceriam nessas visitas, como se fossem "o verdadeiro ponto de chegada de suas expedições" (LIMA, 1971, p. 186 apud SÜSSEKIND, 1990, p. 127). O geógrafo, naturalista e explorador alemão Alexander Humboldt também era amigo de Goethe e Schiller, e é o autor de Kosmos, um influente tratado sobre ciência e natureza publicado entre 1845 e 1862. Daí suspeitarmos que em tal jantar ocorrido em 1804, o viajante de Galáxias ocupa a cadeira do autor de Kosmos na mesa de Goethe.

Também na Alemanha, a cidade de Colônia consta na rota de Campos e é mencionada no relato de Tudela, que a classifica como "a principal do império" (TUDELA, 2017, p. 146). Em Galáxias, no fragmento 16, "um depois um", numa estação de trem em Colônia, o viajante cita o Fausto // de Goethe e vê os olhos da morte. Dentre outras passagens por lugares não vistos, mas registrados por Tudela, apontamos no fragmento 7, "sassamegoto", uma viagem de trem rumo a Praga, que se desdobra em pranto no já citado fragmento 9, "açafrão", no qual velhos senhores choram os judeus mortos em Praga; a cidade é afinal alcançada no fragmento 17, "uma volta inteira", às margens do gelado rio Moldau. Será tal desdobramento mais uma conexão 
com Tudela? Praga é a penúltima localidade referida por Benjamin, que encerra seu relato com uma menção a Paris, "a grande cidade" situada no rio Sena: "Lá existem eruditos sem igual em todo mundo, que estudam a Lei dia e noite" (TUDELA, 2017, p. 148). Mais um espaço deixado por Benjamin seria preenchido por Campos em Galáxias no desdobramento de Paris? Aos "eruditos sem igual", Haroldo de Campos parece somar os artistas na Paris dividida em cinco cantos: No fragmento 13, "esta é uma álea lenda", a cidade é representada com artistas de rua e a torre Eiffel em seu "equilíbrio perfeito"; no fragmento 21, "e brancusi", pressupõe-se o Museu de Arte da Cidade de Paris. No fragmento 38, "o ó da palavra", vemos Santos Dumont em Paris na pintura de Zizi-Sapateiro; no 39, "circulado de violeta", acontece a imersão nos painéis de Monet no Museé L'Orangerie; e no 40, "como quem está num navio", o poeta viajante se encontra no Café de Cluny.

Nota-se que a sequência de fragmentos de Córdoba a Berlim foi redigida entre 1964 e 1965. Um ano depois, em 7 de agosto de 1966, Haroldo de Campos retoma a escrita levando a viagem para terras incógnitas nos tempos de Benjamin de Tudela. O registro poético da visita aos Estados Unidos começa por Manhattan e Nova lorque, no fragmento 24, "a liberdade". A chegada remete à crônica "Edgar Allan Poe" (1896) de Rúben Darío, quando divisa a estátua da Liberdade; na visão do viajante de Campos, "o verde fluoresce" como efeito da oxidação nos "olhos de cobre esbugalhado" da estátua, e logo nos deparamos com norte-americanos que são capazes de "devorar antropófagos de mandíbulas de aço". No deslocamento por Nova lorque, o poeta empresta os olhos de Maiakovski, Oswald de Andrade e Sousândrade, nomeando ruas e praças, entre infernais círculos norte-americanos e letreiros luminosos que estampam nomes de grandes empresas.

Aventados os antropófagos que povoam as crônicas de Conquista, a pena de Campos passa aos astecas no fragmento 25, "aquele como se chamava", que relata a viagem de carro da Cidade do México a Toluga: "miguel com seu perfil de príncipe azteca" conta a viagem de um judeu americano que "se botara de new york a méxico city com a mulher e filhos", e o texto-viagem então se escreve em "amatl", papel com que os astecas confeccionavam seus livros segundo a relação de Bernal Díaz del Castillo, o líder Moctezuma tinha uma biblioteca: "tenía de estos libros una gran casa de ellos" (CASTILLO, 1795, v2, p. 53). 
Da estrada, entre ruínas astecas, a pluma do poeta salta para Boston e descreve a réplica de um templo hindu com imagens de Krishna, seguida da transplantação da igreja da Catalunha "reconstruída dentro do museu café budapest restaurant a boston instituition", ou seja, uma obra arquitetônica é replicada, outra é reconstruída e peça de exposição num museu. Vai a caneta do poeta para Washington e San Francisco, depois a um cabaré de Soho; no fragmento 29, "poeta em lira", deslocamentos se justapõem: na frase de caminhão deduz-se uma estrada, o olhar logo alcança o biombo de um restaurante chinês, depois um poema concreto no subway, então é relembrada uma viagem de trem de Granada a Madrid, e outra de ônibus em Los Angeles. O fragmento 30, "pulverulenda", é ambientado em Buenos Aires e o fragmento 33, "mármore ístrio", passa por Veneza, onde o viajante de Campos destaca os sopradores de vidro, o "mar laguna remanso", a igreja de San Marcos, e desloca-se para a praia na Ligúria, onde viveu Ezra Pound (e recebeu a visita de Campos). O paraíso de Dante é evocado e o canto termina na sacada do albergue, "direttamente al mare dal vostro balcone pescate nel mediterraneo", a o que cabe lembrar que o relato de Tudela revela as rotas comerciais que ligavam os portos do Mediterrâneo; e em algumas cidades os habitantes produzem vidro, como por exemplo, em Antioquia; "dez judeus moram ali dedicados à produção de vidro" (TUDELA, 2017, p. 66). De Veneza, a redação da viagem de Galáxias volta a Washington, então dos negros e do soul.

Na tese Lastro, rastro e historicidades distorcidas: uma leitura dos anos 70 a partir de Galáxias, Lucius Provase defende que o fragmento 34, "calças cor de abóbora", é contextualizado pela descrição do movimento negro em Washington e Filadélfia, e que "As cores chamativas levam a um discurso racial sem cores: 'todas as cores rodeiam o sol'" (PROVASE, 2016, p. 80). Considerando a observação, transcrevemos o verso inteiro e pensamos que o discurso racial também sugere um ritual, quiçá dos "adoradores do sol" constantes no relato de Tudela: "black live black todas as cores rodeiam o sol central furor negro". Na passagem por Khulam, Benjamin de Tudela designa os habitantes como "os filhos de Cusch, que lêem as estrelas, e são todos pretos na cor" (TUDELA, 2017, p. 126). Popularmente, os filhos de Cusch designam os povos africanos de pele negra. Assim sendo, supomos que a releitura de Haroldo de Campos substituiria algumas localidades da África por terras ainda incógnitas no século XII, talvez como forma de representar a diáspora forçada dos povos africanos "pretos na cor", procedimento que 
espelharia a África na América. A partir desta hipótese, a Khulam (Quilon) do relato de Tudela aparece repaginada em Washington nos "zulus guerreiros", "negros de chocolate" e "old black" de roupas coloridíssimas, possíveis equivalentes dos notívagos negros "adoradores do Sol". E as estrelas que eles liam se transformam em estrelas do "soul". A hipótese advém da informação de Tudela sobre a honestidade dos habitantes: "Há um funcionário sentado em seu posto, e o proprietário de qualquer bem perdido tem apenas que descrevê-lo, quando este o devolve" (TUDELA, 2017, p. 127). Campos talvez tenha aproveitado o registro de Tudela na "cafeteria de bloomington", quando o viajante recupera seu "livro de notas de notas para o livro" "nos achados e perdidos entre luvas carretéis e até grampos de cabelo". Também as "bambinas farejadoras de carne crua", no fragmento 36, "eu sei que esse papel", lembram os amigos dos habitantes de Montes de Maisabur registrados porTudela: "vivem de carne crua não cozida. Eles não têm narizes e, em seu lugar têm dois pequenos orifícios, através dos quais respiram" (TUDELA, 2017, p. 120).

Na conjecturada transmutação diaspórica da África, a viagem do poeta de Galáxias chega a Salvador, na Bahia de Gregório de Matos, com negros, indígenas e brancos na festa de lansã, e o ritual africano que é suposição em Washington se realiza textualmente no fragmento 37, "cheiro de urina". Sendo o Brasil o país que abriga o maior número de negros fora do continente africano, e o último a abolir a escravidão, não é impossível que, como em Washington, espelhe a África registrada no relato de Tudela, quando negros já eram inferiorizados, bestializados, capturados em Cusch, e vendidos como escravos:

Quando os homens de Assuan fazem uma incursão em seu país, eles levam consigo pão e trigo, uvas secas e figos, e jogam a comida para essa gente, que corre para pegá-la. É assim que eles trazem de volta muitos deles como prisioneiros, e os vendem na terra do Egito e nos países circundantes. E esses são os escravos negros, os filhos de Ham (TUDELA, 2017, p. 134).

Quatro séculos depois, em diáspora forçada, caravelas abarrotadas de negros arrancados da África aportavam na América tomada dos indígenas por brancos europeus. 
Entre outras possiveis atualizações e espelhamentos realizados por Campos, destacamos no relato de Benjamin de Tudela a passagem por Saída, que é a bíblica Sidon, onde os habitantes estão em guerra com hereges que vivem em cavernas nas montanhas das proximidades, os chamados Drusos: "Eles têm um dia de festa no ano, quando se reúnem, tanto homens como mulheres, para comer e beber juntos, e então intercambiam suas mulheres" (TUDELA, 2017, p. 69). Haroldo de Campos talvez tenha transformado a orgia dos Drusos em orgia intermitente, distribuída por vários cantos de Galáxias, em cidades como Roma, Paris, Washington, São Francisco, Ilha de Lesbos, entre outras. O espalhamento será uma forma de representar a recente diáspora dos palestinos? No relato de Benjamin de Tudela, Jerusalém está situada na Palestina e "cheia de gente que os maometanos chamam de jacobitas, bem como de sírios, gregos, georgianos e francos, e gentes de todas as línguas", e há "cerca de duzentos judeus" (TUDELA, 2017, p. 74). Jerusalém não consta no itinerário de Galáxias, talvez porque a Palestina tem sido apagada do mapa desde 1948, sobrepondo-se o Estado de Israel. Ou teria Haroldo de Campos concebido Granada como Terra Santa? Nesse caso, a composição do livro-viagem começa não pela cidade, mas pelo propósito primeiro de Tudela, mas na cidade em que foi assassinado o poeta Federico García Lorca, que em Galáxias é quem mais se aproxima da figura de 'messias' se pensarmos que a "poesia moderna, como diz Paz, não é serva, mas rival da religião" (PERRONE-MOISÉS, 1998, p. 162). Mas, considerando as dobras galácteas, é possível que Che Guevara seja um "messias" paralelo a Lorca, ideia que advém da comparação de Gabriela Garcia Santos: no fragmento 32, "na coroa de arestas", temos "as imagens conhecidas da morte de Che Guevara: ele está numa madeira, de olhos caídos, barba rala (barbirralo), à semelhança de Cristo" (GARCIA, 2005, p. 77). Talvez nos dignos messias simbólicos, Haroldo de Campos contraste dois messias citados no relato de Benjamin de Tudela, ambos não reconhecidos pelos judeus: Jesus Cristo é referido em algumas passagens; e um contemporâneo de Benjamin de Tudela, o vistoso "David Al-Roy da cidade de Amadia", é um falso messias que diz andar sobre as águas com um manto, entre outros embustes divulgados e vendidos como "milagres" (TUDELA, 2017, p. 114). Em termos poéticogeográficos, localizemos o Mar Morto no caleidoscópico mapa de Galáxias: No fragmento 4, "no jornalário", jaz o "mar morto". N’O itinerário de Benjamin de Tudela, cabe situá-lo nos arredores de Jerusalém, e na cronologia da redação de Galáxias, a travessia do "multitudinous seas" do mar morto "no 
jornalário" é posterior ao fragmento "reza calla y trabaja", ambientado em Granada, talvez Terra Santa de Campos.

Outra possível atualização das observações de Tudela por Haroldo de Campos é o petróleo que no século XII era apenas um medicamento: em Sorrento, "uma fonte brota do fundo do solo contendo o óleo que é chamado de petróleo. As pessoas coletam-no da superfície da água e usam-no para fins medicinais" (TUDELA, 2017, p. 53). Em Galáxias o petróleo aparece processado como plástico poluindo oceanos, e como combustível movendo meios de transportes e enriquecendo "círculos" norte-americanos.

Quase toda a sequência de fragmentos escritos entre 1966 e 1968 situa a viagem em terras incógnitas nos tempos de Tudela, no entanto, lugares por ele visitados se desdobram ou reverberam nas diásporas, nas transposições e simulações, são, portanto, transpostos aos pedaços, em museus, galerias, restaurantes, consultórios, casas noturnas, casas de massagem, etc. Índia, Babilônia e China são aventadas em fragmentos também escritos em sequência; no museu café em Boston, há uma réplica de um templo hindu, com imagens de Krishna. No fragmento 42, "a criatura de ouro", vem o "sopro birhaspati" e uma visão dos "jardins suspensos", expressões que pressupõem tanto a Índia como a Babilônia visitada por Benjamin de Tudela, que faz referência às ruínas do palácio de Nabucodonosor habitada por escorpiões e serpentes, e descreve a Torre de Babel. À confusão das línguas e queda da torre, podemos associar os muitos idiomas misturados ao português nos versos de Galáxias, tema bíblico abordado no texto de Haroldo de Campos dedicado a Walter Benjamin. Observa Eduardo Jorge que "Haroldo retorna à perda da língua única, resultado da expulsão do homem do paraíso", citação que pode ser entendida como uma informação de "que a paródia é capaz de absorver formas históricas, além de conter a dimensão prática de memorizálas ou de transportá-las de um contexto literário a outro". Jorge destaca também a observação de Campos acerca da designação e procedência de babel, "que significa misturar" (CAMPOS, 1997, pp. 156-158 apud JORGE, 2019, p. 94).

Tudela não chegou à China como Marco Polo, mas foi o primeiro europeu a menciona-la, limitando-se aos "ventos tempestosos" que confinam embarcações no mar de Nipka, e à descoberta de "um estratagema para escapar desse maldito lugar": A tripulação se envolve em pele de boi e mergulha no mar. "Um grande pássaro chamado grifo vigia-os e, na crença de 
que o marinheiro é um animal, o grifo agarra-o, leva-o para a terra firme e o depõe no alto de uma montanha ou em uma cova" (TUDELA, 2017, p. 132). A China não consta no itinerário de Galáxias, mas se desdobra imagéticamente no biombo de um restaurante chinês no fragmento 29, "poeta sem lira"; no fragmento 40, "como quem está num navio", nos palitos chineses do I Ching (que pressupõe o método do compositor John Cage); e no fragmento 41, "tudo isto tem que ver", eis a China numa sessão de acupuntura, nos quadros e agulhas do suplício chinês. O grifo sobrevoa algumas passagens de Galáxias, e dentre os meios de transporte referidos no relato de Tudela, exatamente o grifo é o que há de mais próximo ao avião, veículo em que se encontra o viajante de Galáxias no fragmento 21, "e brancusi", de Stuttgart rumo a Paris. O grifo é também mencionado nas viagens de Marco Polo, nas Mil e uma noites, e estampa o Brasão das Armas de Portugal, a partir do qual Fernando Pessoa compõe Mensagem, obra talvez aludida no fragmento 4, e reiterada no 44: "há uma vis de mensagem": Portugal é "portogalo" e o Brasil "brasilisco", ou seja, o poeta faz um trocadilho com basilisco, uma figura da heráldica tal qual o grifo, detalhe significativo em se tratando de uma composição especular, visto que a técnica mise en abyme provém dos brasões - mais um desdobramento, afinal.

Dos países orientais, o Japão é aventado em Galáxias entre alusões a haicais de Bashô e Buson no fragmento 7, "sasamegoto", em que ocorrem duas viagens, uma de carruagem em Kioto, outra de trem rumo a Praga, penúltima cidade d'O itinerário de Benjamin de Tudela. Às fantasiosas descrições de lugares como Bagdá, onde Tudela também não chegou, Haroldo de Campos parece trazer a Galáxias na descrição de mesquitas e arabescos, na evocação ao Livro das mil e uma noites e na "scherezada" que figura entre fadas e princesas no fragmento 47, "passatempos e matatempos". Nota-se que a escrita se esparsa e a geografia some do mapa do fragmento 43 ao 47, que mais se voltam ao livro e à linguagem. O fragmento 48, "nudez", escrito em 1973, se desenrola numa casa de massagem de New York e evoca Homero e a antigidade grega. No ano seguinte, a escrita de Campos se volta a uma morte em Blumenau, no penúltimo fragmento. E independente da rota escolhida pelo leitor, a viagem termina no "fim do mundo" do formante 2 , escrito entre novembro de 1975 e março de 1976. Como sabemos, o texto integral de Galáxias foi publicado em 1984, duas décadas depois do início da composição. 
Se por um lado o processo de escrita coincide com a duração da viagem de Benjamin de Tudela, por outro, a temporalidade no segundo e no penúltimo fragmento reitera o "poema circular", talvez tido em conta no processo de escrita, visto que a morte do Dr. Fritz comentada no fragmento 49, "a dream that hath no bottom", ocorre em 1897, ano véspera do nascimento de Federico García Lorca, cuja morte ecoa no segundo fragmento, ambientado em Granada.

Muito longe de esgotar as investigações da possível releitura de $O$ itinerário de Benjamin de Tudela, ou da "paródia" de guia de viagem que teria realizado Haroldo de Campos em Galáxias a partir deste guia de viagem medieval, concluímos o artigo reiterando a suposição de no caleidoscópico neobarroco Galáxias, entre outros procedimentos, Campos teria integrado a permutação e o movimento do "multilivro" de Mallarmé, o jogo proposto por John Cage e o acaso balizado através de "formantes" por Boulez. A viagem em Galáxias pressupõe o aspecto de "mapa" da partitura de Stockhasen, e grande parte das cidades visitadas ou aludidas pelo viajante parecem espelhar ou desdobrar localidades visitadas e mencionadas por Benjamin de Tudela, como se compusesse Campos um "canto paralelo", ainda trabalhando conceitos percebidos no documento medieval. Tendo em conta as semelhanças e possíveis equivalências do trajeto de Tudela no roteiro da redação de Haroldo de Campos, lançamos a hipótese de que $O$ itinerário de Benjamin de Tudela foi um possível guia no processo da composição de Galáxias, e sem ignorar a possibilidade de leitura aleatória, priorizamos a linearidade do itinerário e da escrita, e elaboramos a análise comparativa seguindo a cronologia de redação dos fragmentos, mas como se tivéssemos em mãos mapas e plantas das duas obras que confrontamos. Por fim, chegamos ao mar da última página de Galáxias: no formante 2, "a mão treme a nave encalha", o poeta parece admitir o fracasso na escritura e aceitar a épica morte na praia, e eis a tábua de salvação: "mas tua alma está salva", "pois o livro é o teu porto velho". A "voz" do texto presta tributo a Dante e Galáxias acaba em dança: "mente quase-íris se emparadiza neste multilivro e della doppia danza". O formante 2, "fecho encerro", também inteiramente escrito em itálico, espelha o formante inicial, e Galáxias finda "obra aberta", opostamente a O itinerário de Benjamin de Tudela, documento histórico que se encerra "Terminado e Completado". 


\section{referências}

ALBERTI, Rafael. A León Felipe, en su homenaje. El País, 4 de mayo de 1976.

ALBUQUERQUE FILHO, Dhynarte. Haroldo e as Galáxias: um caso concreto de barroco. Conexão - Comunicação e Cultura, UCS, Caxias do Sul, v. 5, n. 9, p. 175-195, jan./jun. 2006.

ANDRADE, Gênese. Entre a impressão e o inapreensível: Haroldo de Campos segundo Jacó Guinsburg. In. Signâncias: reflexões sobre Haroldo de Campos (org. André Dick), São Paulo, Risco Editorial, 2010, p. 116-146.

BOSI, Alfredo. Poesia resistência. In: O ser e o tempo da poesia. São Paulo: Cultrix, 1983.

BRITTO, Paulo Henriques. Poesia e memória. In: Mais poesia hoje (org. Celia Pedrosa). Rio de Janeiro: 7 Letras, 2000.

CAMPOS, Haroldo de (1984). Galáxias. São Paulo: Editora 34, 2011.

. A arte no horizonte do provável. São Paulo: Editora Perspectiva, 1969.

A escritura mefistofélica: paródia e carnavalização no Fausto de Goethe, Tempo brasileiro, n. 62, julho-setembro, 1980, p. 129.

- Breve cronologia da vida e obra de Haroldo de Campos. In: Signâncias: reflexões sobre Haroldo de Campos (org. André Dick), São Paulo: Risco Editorial, 2010.

A língua pura na teoria da tradução de Walter Benjamin. Revista USP, n. 33, 1997, p. 163.

CASTILLO, Bernal Díaz del (1632). Historia verdadera de la conquista de la Nueva España. Biblioteca Saavedra Farjado de Pensamiento Político Hispánico, 1795.

CASTRO, Ana Caroline Silva e. Apreensão de livros tidos como subversivos: o que os processos judiciais da Ditadura Militar revelam. Tese de doutorado. Escola de Comunicação e Artes da Universidade de São Paulo, 2017.

CEMBRANO, Jorge Manzi. La prosa semi-abstrata de Haroldo de Campos - una aproximación a los textos tardíos de Galáxias. Literatura e sociedade (USP), São Paulo, v. 29, p. 86-104, 2019. 
COLÓN, Cristóbal (1493). Los cuatro viajes del Almirante y su testamento Relación compendiada por Fray Bartolomé de las Casas. Edición y prólogo de Ignacio B. Anzoátegui. Coleção Austral, n 633, Espasa Calpe, 1991.

FELIPE, León. Antología rota. Colección Letras Hispánicas, Cátedra, 2008.

GARCIA, Marília. Velocidades e vozes: formas de estruturação das Galáxias de Haroldo de Campos. Tese (Mestrado em Letras) - Universidade Estadual do Rio de Janeiro, 2005.

GRAMSCI, Antonio. Obras escolhidas. Lisboa: Estampa, vol.II, 1974.

JORGE, Eduardo. Paródias do céu: a poesia, a crítica e a tradução de Haroldo de Campos. Revista Circuladô, Risco Editorial. São Paulo, Ano VII, v.10, p. 8799, 2019.

LIMA, José Lezama. Recuerdo de Humboldt. In. Algunos tratados en la Habana. Barcelona: Editorial Anagrama, 1971.

LIMA, Luiz Costa. A aguarrás do tempo: estudos sobre a narrativa. Rio de Janeiro: Rocco, 1989.

LUKÁCS, György. Marxismo e teoria da literatura. São Paulo: Expressão Popular, 2012.

OLIVEIRA, Ana Lucia. Os fragmentos do real em Galáxias, de Haroldo de Campos. Revista Letras. Curitiba, no 84, jul./dez. p.47-57: Editora UFPR, 2011.

PRAZERES, Armando Sérgio. Haroldo de Campos e o Barroco: a criação de ou(t)ro - ensaios para um guia das Galáxias. Dissertação (Doutorado em Letras). Universidade do Rio Grande do Norte, 2016.

PEREIRA, Cristina Monteiro de Castro. Revendo estrelas em outras galáxias. In: Signâncias: reflexões sobre Haroldo de Campos (org. André Dick). São Paulo: Risco Editorial, 2010.

PERRONE-MOISÉS, Leyla. Altas Literaturas. São Paulo: Companhia das Letras, 1998.

. A inútil poesia de Mallarmé. In: Inútil Poesia. São Paulo: Companhia das Letras, 2000.

. Viajando com Haroldo. In Signâncias: reflexões sobre Haroldo de Campos (org. André Dick), São Paulo, Risco Editorial, 2010. 
PROVASE, Lucius. No estudo Lastro, rastro e historicidades distorcidas: uma leitura dos anos 70 a partir de Galáxias. Dissertação (Doutorado em Letras) Universidade de São Paulo, 2016.

SOUZA, Gabriela Beatriz Moura Ferro Bandeira de. Neobarroco, Neobarroso, Transbarroco-uma leitura do barroco nas obras literárias de Haroldo de Campos e Néstor Perlongher. Dissertação (Doutorado em Letras) - Universidade de São Paulo, 2017.

SÜSSEKIND, Flora. O Brasil não é longe daqui. São Paulo: Companhia das Letras, 1990.

- Literatura e vida literária-Polêmicas, diários e retratos. Rio de Janeiro: Jorge Zahar, 1985.

TODOROV, Tzvetan. Os Homens-Narrativas. In: As estruturas narrativas. São Paulo: Editora Perspectiva, 2018.

TUDELA, Benjamin de (1160-1173). O itinerário de Benjamin de Tudela. Organização, tradução e notas de Jacó Guinsburg. São Paulo: Perspectiva, 2017.

. Viajes de Benjamin deTudela. Trad. Ignacio Gonzales Llubera. Madrid: V.H. Sanz Calleja, 1918.

WROBEL, Jasmin. "Construyendo puentes: Haroldo de Campos como mediador cultural entre Brasil e Hispanoamérica". In: Sophia Austral, n 15, p. $27-44,1^{\circ}$ Semestre, 2015.

Artigo recebido em: 31/01/2020 Aceito em: 22/06/2020 